\title{
Zinc oxide films prepared by spray pyrolysis
}

\author{
Andrzej Maciąg ${ }^{1}$, Piotr Sagan ${ }^{1}$, Marian Kuźma ${ }^{1}$, Volodymyr Popovych ${ }^{2}$ \\ ${ }^{1}$ Centre for Innovation and Transfer of Natural Sciences and Engineering Knowledge, \\ University of Rzeszów, S. Pigonia 1, 35-959 Rzeszów, Poland \\ ${ }^{2}$ Department of Fundamental Technologies, Ivan Franko Drogobych State Pedagogical University, \\ 24 Ivan Franko str., 82100, Drogobych, Ukraine
}

\begin{abstract}
In this work we developed and tested spray pyrolysis system for layers deposition. In the system we have used ultrasonic apparatus (nebulizator) as a sprayer. A zinc nitrate aqueous solution has been used as a precursor solution. The idea of the method is the decomposition of nitrate on a hot substrate according to the reaction $\mathrm{Zn}\left(\mathrm{NO}_{3}\right)_{2} \rightarrow \mathrm{ZnO}+2 \mathrm{NO}_{2}+1 / 2 \mathrm{O}_{2}$. The layers were grown on glass, $(001) \mathrm{Si}$ and $\mathrm{KCl}$ substrates at the temperatures $300-500^{\circ} \mathrm{C}$. The thickness of the obtained layers was in the range $50-$ $500 \mathrm{~nm}$, depending on the growth time and rate. The influence of substrate temperature on the morphology of the layers has been studied by SEM method. The energy gap of the layers was found to be the range of 3.26-3.3 eV from their absorption spectra.
\end{abstract}

\section{Introduction}

In the early 2000s T. Dietl and H. Ohno [1] predicted theoretically high temperature ferromagnetism in $\mathrm{ZnO}: \mathrm{Mn}$ diluted magnetic semiconductor (DMS), which make it very prospective material for spintronic application. Basing on a Zener model of ferromagnetism [2], they calculated the value of Curie temperature in the range of $300-400 \mathrm{~K}$ for $\mathrm{InN}, \mathrm{GaN}$ and also $\mathrm{ZnO}$ with $5 \%$ content of $\mathrm{Mn}$ and high hole concentration (more than $3.5 \cdot 10^{20} \mathrm{~cm}^{-3}$ ). Although after huge number of works with synthesis of such a materials the idea of room temperature DMS has not been verified experimentally for this material [3, 4], $\mathrm{ZnO}$ thin films have many other practical application as a material for variety of optoelectronic and electroacoustic devices (see e.g. the review paper [5]). In numerous laboratory $\mathrm{ZnO}$ thin films were deposited by well-known techniques, such as molecular been epitaxy [6, 7], magnetron sputtering [8], chemical vapor deposition [9], pulsed-laser deposition [10] and atomic layer deposition [11, 12]. In this paper we have applied spray pyrolysis method, which is more rarely used for the sake of thin layers or nanoparticles fabrication. Normally, this method are applied for fabrication of thin-film gas sensors (e.g. $\mathrm{SnO}_{2}$ ) and conducting and transparent ZnO:In layers [5], as well as for carbon coating of electrodes in fuel cells technology and in lithium-ion batteries production. The main advantages of the spray pyrolysis are small cost of the set up, flexibility of the process, low temperature and vacuum less processing, uniform layer coating, possibility of coating of large area substrates. The aim of present paper is to prepare $\mathrm{ZnO}$ thin layers by pyrolysis method $[13,14]$ and test their structural and optical quality. For our purposes, we have developed a homemade system for small $\left(5 \times 5 \mathrm{~mm}^{2}\right)$ and large $(10 \times 10$ $\mathrm{cm}^{2}$ ) area layer deposition. We have obtained $\mathrm{ZnO}$ layers using $\mathrm{Zn}\left(\mathrm{NO}_{3}\right)_{2}$ as a precursor. For structural measurements the layers were grown on $\mathrm{Si}$ substrates, whereas glass substrates were used for optical and electrical characterization of the grown layers.

\section{Experimental}

\subsection{A homemade system for spray pyrolysis}

A homemade apparatus for spray pyrolysis (Fig. 1) consists of ultrasonic nebulizer, nozzle, and heating plate. An air was used as a carrier gas. Ultrasonic nebulizer is connected with air pump and with nozzle mounted on $\mathrm{X}-\mathrm{Y}$ throat. The position and movement of the nozzle in $\mathrm{X}-\mathrm{Y}$ plane was controlled by computer. Deposition was carried out via scanning the surface of the substrate by nozzle in 20 rows, each of $3 \mathrm{~mm}$ wide. The flow of air gas was controlled by flow meter. Heating plate was equipped with contact thermometer and temperature controller. The temperature was changed in the range of $100-600^{\circ} \mathrm{C}$. Single crystalline (100)-oriented $\mathrm{Si}$, glass and single crystalline $\mathrm{KCl}$ were used as substrates. The deposition of the layers was carried out at various technological parameters:

1. The distance of nozzle - substrate: $1,2,3$ and $4 \mathrm{~cm} ; 2$. Flow of air: $3.3 \mathrm{~min}^{-1} ; 3$. Temperature of substrate: $200-$ $600^{\circ} \mathrm{C}$; 4. Concentration of precursor in water: $0.1 \mathrm{M}$.

All samples presented in this paper were deposited onto substrates heated to the $600{ }^{0} \mathrm{C}$, at precursor concentration of $0.1 \mathrm{M}$ and nozzle-substrate distance of $20 \mathrm{~mm}$. 


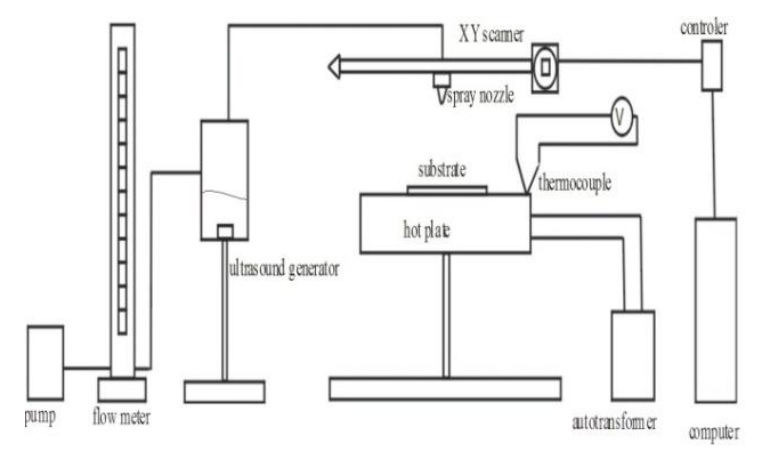

Fig. 1. Spray pyrolysis system.

Zinc nitrates appear in the form of four hydrated and one anhydrous (Table 1).

Table 1. Forms of zinc nitrates and their melting temperatures.

\begin{tabular}{|c|c|}
\hline Form of $\mathrm{Zn}\left(\mathrm{NO}_{3}\right)_{2}$ & Melting point $[\mathrm{K}]$ \\
\hline $\mathrm{Zn}\left(\mathrm{NO}_{3}\right)_{2} \cdot \mathrm{H}_{2} \mathrm{O}$ & 343,9 \\
\hline $\mathrm{Zn}\left(\mathrm{NO}_{3}\right)_{2} \cdot 2 \mathrm{H}_{2} \mathrm{O}$ & 328,6 \\
\hline $\mathrm{Zn}\left(\mathrm{NO}_{3}\right)_{2} \cdot 4 \mathrm{H}_{2} \mathrm{O}$ & 317,9 \\
\hline $\mathrm{Zn}\left(\mathrm{NO}_{3}\right)_{2} \cdot 6 \mathrm{H}_{2} \mathrm{O}$ & 308,3 \\
\hline $\mathrm{Zn}\left(\mathrm{NO}_{3}\right)_{2}$ & $\begin{array}{c}623 \text { (decomposition } \\
\text { temperature) }\end{array}$ \\
\hline
\end{tabular}

Thermal decomposition of zinc nitrates was extensively studied by B. Malecka [15] by using of mass spectroscopy technique. The decomposition is a many stage chemical process via intermediate products. In our experiment we were working with heksahydrate $\mathrm{Zn}\left(\mathrm{NO}_{3}\right)_{2} \cdot 6 \mathrm{H}_{2} \mathrm{O}$. At $338 \mathrm{~K}$ an intermediate compound $\mathrm{Zn}\left(\mathrm{NO}_{3}\right)_{2} \cdot \mathrm{Zn}(\mathrm{OH})_{2} \cdot 2 \mathrm{H}_{2} \mathrm{O}$ are formed during slow thermal decomposition. At $393 \mathrm{~K}$ another compound, $\mathrm{Zn}\left(\mathrm{NO}_{3}\right)_{2} \cdot 2 \mathrm{Zn}(\mathrm{OH})_{2}$, is formed. In general, the kind of the intermediate phase depends on the temperature and heating rate [15]. At temperature greater than $250^{\circ} \mathrm{C}$ the metastable phases transform into $\mathrm{ZnO}$. Besides of $\mathrm{ZnO}$, oxygen and nitrogen oxides are the final products. If the temperature of pyrolysis was too low, the residual of nitrogen intermediate products were observed in the layers by registering their different colors. Scheme of the thermal decomposition of $\mathrm{Zn}\left(\mathrm{NO}_{3}\right)_{2} \cdot 6 \mathrm{H}_{2} \mathrm{O}$ can be written as [16]:

$$
\mathrm{Zn}\left(\mathrm{NO}_{3}\right)_{2} \rightarrow\left\{\begin{array}{c}
\mathrm{Zn}(\mathrm{OH})_{2} \\
\mathrm{Zn} \mathrm{O}_{2}\left(\mathrm{NO}_{3}\right)_{2} \\
\mathrm{Zn}(\mathrm{OH})\left(\mathrm{NO}_{3}\right)
\end{array}\right\} \rightarrow \mathrm{ZnO}+y N_{w} \mathrm{O}_{x}+z \mathrm{O}_{2}
$$

\subsection{Characterization of the layers}

Structure of the layers, deposited onto glass substrates, was investigated using optical microscopy. The films, grown on $\mathrm{Si}$ and glass substrates, were studied by means of scanning electron microscopy (SEM) using Vega 3 Tescan electron microscopy $(\mathrm{U}=25 \mathrm{kV})$. The composition of the layers was measured by energy dispersive X-ray (EDS) method on this electron microscopy equipped with Bruker Quatax software and $10 \mathrm{~mm}^{2}$ area, $126 \mathrm{eV}$ resolution detector. The measurements absorption spectra for determination of the layers' energy gap were carried out on Carry UV-
3100 spectrometer in the wavelength range of $200-$ $1200 \mathrm{~nm}$.

\section{Results and discussion}

Solid zinc nitrate begin to decompose thermally at $350^{\circ} \mathrm{C}$. However, the start of spray pyrolysis with aqueous solution of zinc nitrate was observed at lower temperatures $150-170^{\circ} \mathrm{C}$. Studenikin et al. [16] showed that the layers obtained in such low temperatures are of bad quality. The critical temperature of $180^{\circ} \mathrm{C}$ has been introduced, above this temperature (at $180-400^{\circ} \mathrm{C}$ ) the layers are very smooth to the eye and almost transparent. In Table 2 the preparation conditions of the investigated layers are collected.

Fig. 2 presents SEM images of the $\mathrm{ZnO}$ layers obtained on the chemo-mechanically polished and mirror-like (100)-oriented surface of single crystalline $\mathrm{Si}$. The layers were deposited at $300^{\circ} \mathrm{C}, 400^{\circ} \mathrm{C}$ and $500^{\circ} \mathrm{C}$. Low magnification images $(\mu \mathrm{m}$-scaled) of the layers are presented on the left panel of Fig. 2, while the images in a greater magnification are collected on the right panel. Photos on the right indicate good morphology of the proper layers, without drops visible on the left images. The layers contain drops with diameter of about $2 \mu \mathrm{m}$ (Fig. 2 a, c, e), which is the same for each temperature of pyrolysis. The value of the drop on the films surfaces corresponds well with that of drops in aqueous solution of zinc nitrate in aerosol. However, the morphology of the drops changes with the increase of the growth temperature. At $300^{\circ} \mathrm{C}$ drops are of regular form, at $400^{\circ} \mathrm{C}$ some drops have holes inside (Fig. 2c) and at $500^{\circ} \mathrm{C}$ a number of drops are in the form of the rings with well-defined outside faces (Fig. 2e). Such a change of the drops morphology reflects the corresponding steps of process evolution during the thermal decomposition of the solution of the precursor. The sequence of the decomposition is as follows (Fig. 3): atomization $\rightarrow$ solvent evaporation by diffusion $\rightarrow$ shell formation $\rightarrow$ evaporation by open shells $\rightarrow$ decomposition of particles or shells $\rightarrow$ crystallization.

The rate of evolution presented in Fig. 3 depends on time of the thermal treatment of the particles and on temperature of the substrate. The size of the particles also influences the morphology of final product. In the scanning method of layers formation the time of deposition is much shorter in respect to the time of "thermal annealing" during deposition and after deposition (cooling of the sample). Therefore, we relate the change of morphology with the annealing of the samples. In Fig. 2a one can notice solid particles with very rough shell. It means that at this temperature the process of evaporation was not finished. At growth temperature $400^{\circ} \mathrm{C}$ solid shells are visible and some of them are damaged and empty inside. It is clear from Fig. 2e that the temperature $500^{\circ} \mathrm{C}$ was high enough in order that all drops become hollow.

Most of the shells are crushed forming flat layer, which structure is not observable by SEM microscope even at considerably high magnification (Fig. 2f). 
Table 2. Technological parameters of the $\mathrm{ZnO}$ thin films, chosen for the studies $(\mathrm{C}$ is a concentration of precursor, $\mathrm{D}$ is a spray nozzle - substrate distance, $\mathrm{t}_{\mathrm{p}}$ is a time of pyrolysis).

\begin{tabular}{|c|c|c|c|c|c|c|c|}
\hline $\begin{array}{c}\text { Sample } \\
\text { No. }\end{array}$ & $\mathrm{T}\left({ }^{\circ} \mathrm{C}\right)$ & Substrate & $\begin{array}{c}\text { Thickness } \\
{[\mathrm{nm}]}\end{array}$ & $\begin{array}{c}\mathrm{C} \\
(\mathrm{M})\end{array}$ & $\begin{array}{c}\mathrm{D} \\
(\mathrm{mm})\end{array}$ & $\begin{array}{c}\mathrm{t}_{\mathrm{p}} \\
(\mathrm{s})\end{array}$ & Results \\
\hline 39 & 300 & $\mathrm{Si}(001)$ & 40 & 0.1 & $30 \pm 1$ & $600 \pm 1$ & SEM \\
\hline 52 & 400 & $\mathrm{Si}(001)$ & 80 & 0.1 & $20 \pm 1$ & $600 \pm 1$ & SEM \\
\hline 41 & 500 & $\mathrm{Si}(001)$ & 70 & 0.1 & $20 \pm 1$ & $600 \pm 1$ & SEM \\
\hline 36 & 300 & glass & 40 & 0.1 & $20 \pm 10$ & $600 \pm 1$ & SEM \\
\hline 53 & 300 & glass & 40 & 0.1 & $20 \pm 1$ & $600 \pm 1$ & $\mathrm{R}(\mathrm{t})$ \\
\hline
\end{tabular}

a)

c)

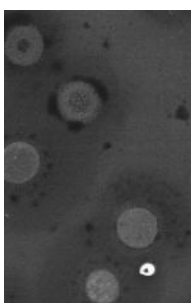

SEM HV: $30.0 \mathrm{kV}$ SEM MAG: $4.51 \mathrm{kx}$ WD: $7.46 \mathrm{~mm}$ Det: SE (9)
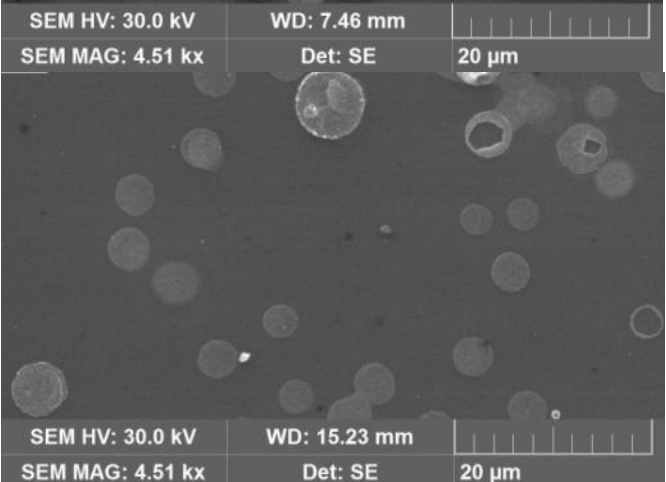

e)

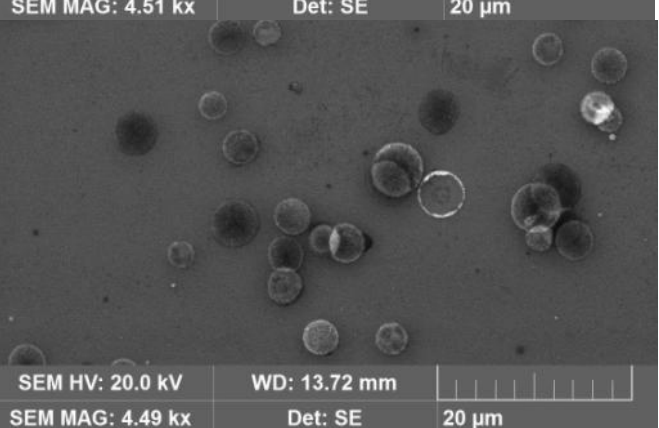

b)

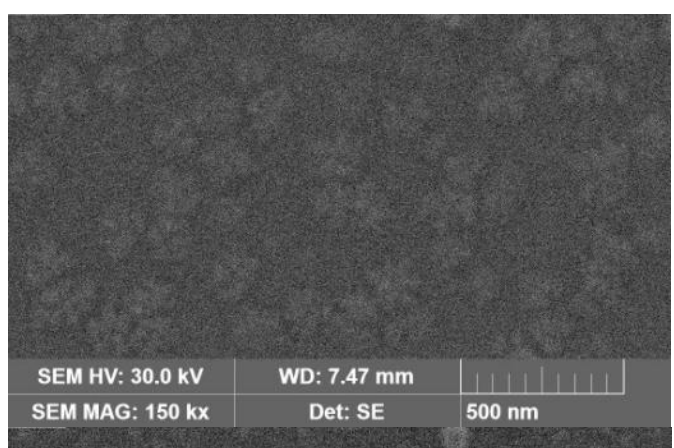

d)

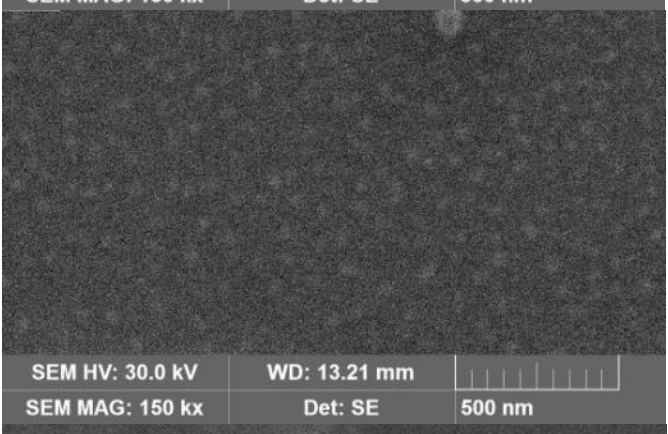

f)

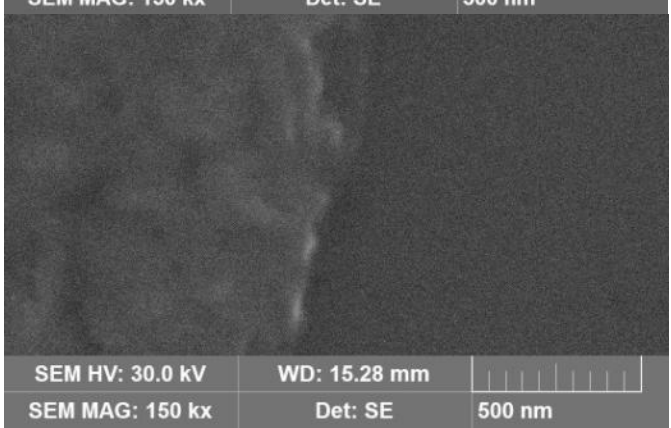

Fig. 2: SEM images of the samples No. 39 (a, b), No. 52 (d, e) and No. 41 (e, f) obtained at temperatures $300^{\circ} \mathrm{C}, 400^{\circ} \mathrm{C}$ and $500^{\circ} \mathrm{C}$, respectively. 


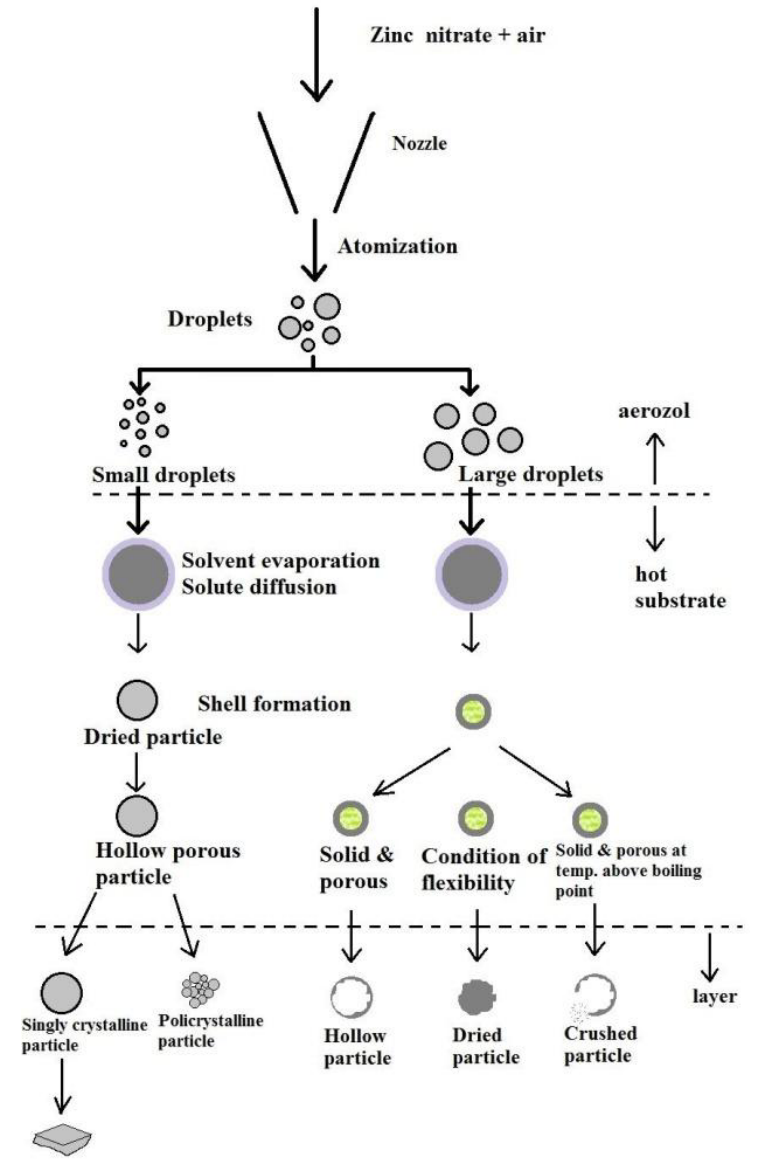

Fig. 3. Evolution of decomposition of the droplets in spray pyrolysis method (reproduced from Fig. 1 of paper [13]).

In Fig. 2c single particles (dark balls) are visible as well. The structure of these balls was not investigated in the present paper. The proper layer obtained at $300^{\circ} \mathrm{C}$ (Fig. $2 \mathrm{~b})$ has fractal structure [17]. It consists from aggregates (with diameter about $500 \mathrm{~nm}$ ) built from the small individual $10 \mathrm{~nm}$-sized particles. These later are composed from the smaller ones, etc. Such morphology is not observed for the layers obtained at $400^{\circ} \mathrm{C}$ and at $500^{\circ} \mathrm{C}$ (see Fig. 2 d, f). Chemical composition of layers measured by EDS method points on good stoichiometry 1:1. [Fig.4]. Due to a small thickness of the layers (tens nanometers ) the EDS accuracy of the measure is not high. Therefore, the layer measured was spited from the substrate and composition of obtained powder of $\mathrm{ZnO}$ was determined.

The results EDX measurements, shown in Fig. 4, indicated deviation of the stoichiometry of the obtained films to oxygen-enriched side. But exact determination of their composition is hindered by the fact that generation region of characteristic $\mathrm{X}$-rays in $\mathrm{ZnO}$ in EDX method is higher than thickness (tens of nanometers) of the layers. Therefore, substrates could contribute to the recorded EDX signal, lowering the accuracy of the analysis.
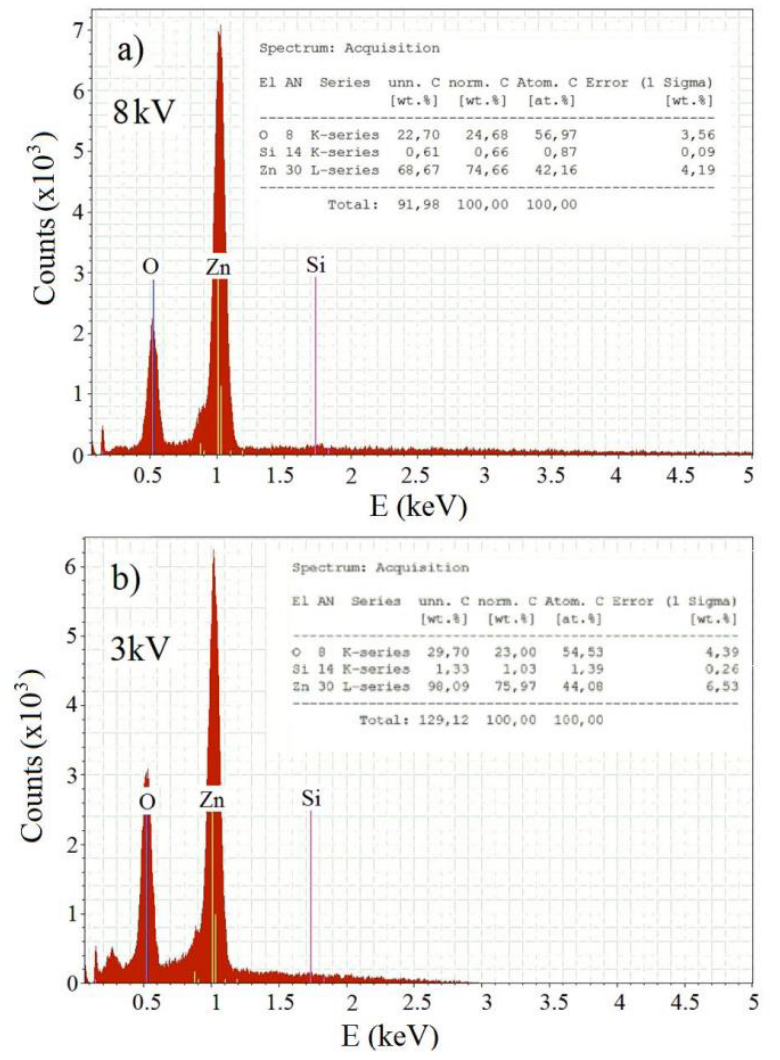

Fig. 4. Composition of the layers No. 36, measured by EDX at the applied voltages of $8 \mathrm{kV}$ (a) and $3 \mathrm{kV}(\mathrm{b})$.

Transmission spectrum of the sample No. 53 (Fig. 5a) revealed very sharp absorption edge, which are typical for most of the layers obtained in this work. In Fig. 5b spectral dependence in the narrower interval near the fundamental absorption edge is presented. Although the dependence is not exactly linear at this energy range, we determined the energy gap $E_{g}$ using formulae for the direct interband transitions:

$$
\alpha \cdot h v=C\left(h v-E_{g}\right)^{\frac{1}{2}}
$$

where $h v$ is a photon energy. We obtained the values in the range $3.24-3.30 \mathrm{eV}$ for the several measured samples, which are less values compared to those $(3.3 \mathrm{eV})$ reported by Studenikin et al. [16]. We did not notice any dependence of the energy gap on the temperature of pyrolysis.

All samples were of high electrical resistance (more than $1 \mathrm{M} \Omega$ ), as it was determined by two-contact method. Their photoconductive relaxation was tested using mercury lamp equipped with ultraviolet filter. Measurements of transient photoconductivity after switching of the lamp revealed long (tens of minutes) relaxation time (Fig. 6), the exact nature of which is not clear yet. 

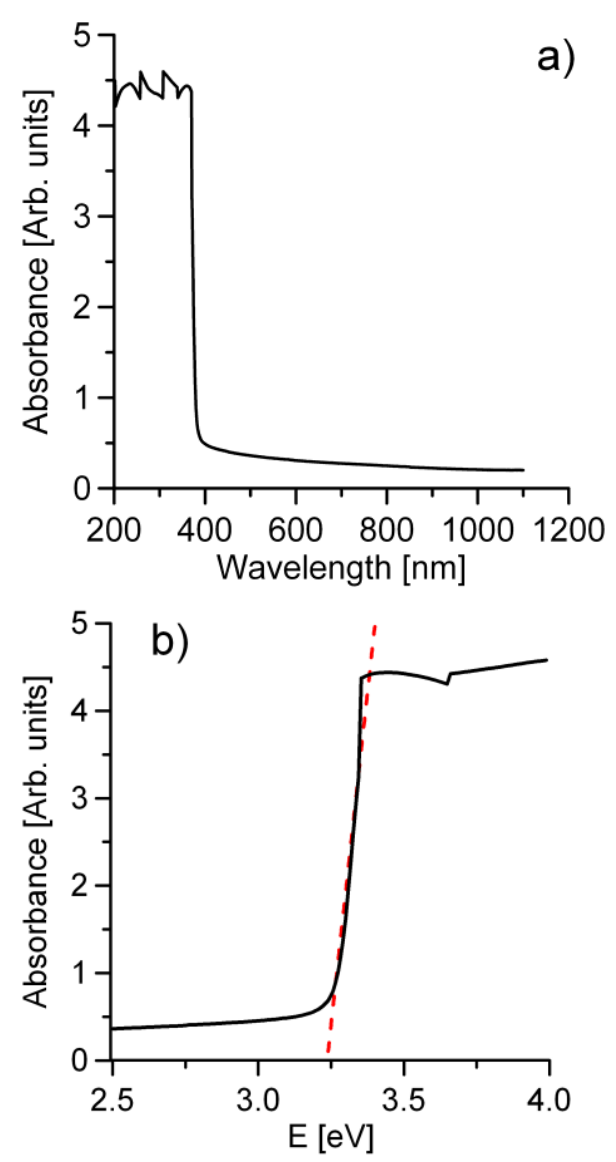

Fig.5: Absorption spectrum of the sample No. 36.

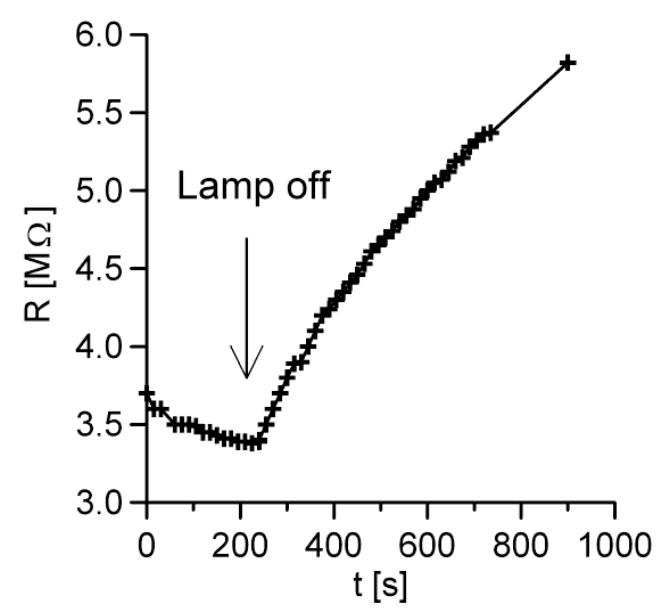

Fig.6: Relaxation of photoresistance for the sample No. 53.

\section{Conclusions}

The ultrasound spray pyrolysis is an advantage technique for thin films fabrication. It is unexpensive and vacuumless method suitable for mass production of selected semiconductor films, such as $\mathrm{ZnO}$ and $\mathrm{CuO}$. These materials are good candidates for photovoltaic industry due to the low cost of $\mathrm{Zn}$ and $\mathrm{Cu}$ metals. In this paper we presented a simple homemade system for pyrolysis, which is proved to be suited for fabrication of both small and large-area (up to $10 \times 10 \mathrm{~cm}^{2}$ ) $\mathrm{ZnO}$ thin films. The morphology of the deposited films indicated their polycrystalline character regardless of the structure of the used substrate (single crystalline (100)-oriented Si or amorphous glass). The size of crystallites in the deposited layer can be controlled by tuning the size of droplets in the spray, which is controlled by the parameters of the spray generator. SEM studies of the layers obtained at $300^{\circ} \mathrm{C}, 400^{\circ} \mathrm{C}$ and $500^{\circ} \mathrm{C}$ confirmed the model of evolution of morphology of zinc nitrate drops during the pyrolysis process, previously published by K. Okuyama et al. [13]. The deposited layers demonstrated good optical quality and crystallinity, being almost transparent in the visible region of the spectrum, and are characterized by sharp absorption edge (having small tail only), which is not dependent on the technological parameters of layers fabrication. The obtained layers are of high electrical resistance (in order of $\mathrm{M} \Omega$ ) and show longtime (up to tens of minutes) characteristic relaxation of photoelectrical response.

\section{Acknowledgments}

This work was supported by Centre for Innovation and Transfer of Natural Science and Engineering Knowledge at the University of Rzeszow ( Poland ).

\section{References}

1. T. Dietl, H. Ohno, F. Matsukura, Phys. Rev. B, 63,195205, (2001)

2. C. Zener, Phys. Rev. 81, 440 (1950)

3. T. Dietl, Nature Mater. 9, 965-974 (2010)

4. S. J. Pearton, C. R. Abernathy, M. E. Overberg, G. T. Thaler, D. P. Norton, N. Theodoropoulou, A. F. Hebard, Y. D. Park, F. Ren, J. Kim and L. A. Boatner, J. Appl. Phys., 1, 93 (2003)

5. Ü. Özgür, Ya. I. Alivov, C. Liu, A. Teke, M. A. Reshchikov, S. Doğan, V. Avrutin, S.-J. Cho and H. Morkoç, J. Appl. Phys. 98, 041301 (2005)

6. Zhengwu Jin, T. Fukumura, M. Kawasaki, K. Ando, H. Saito, T. Sekiguchi, Y. Z. Yoo, M. Murakami, Y. Matsumoto, T. Hasegawa, and H. Koinuma, Applied Physics Letters 78, 3824 (2001)

7. David C. Look, D. C. Reynolds, C. W. Litton, R. L. Jones, D. B. Eason, and G. Cantwell, Appl. Phys. Lett., 81, No. 10, 1830 (2002)

8. Kachirayil J. Saji, Sascha Populoh, Ayodhya N. Tiwari and Y. E. Romanyuk, Phys. Stat. Sol. A 210, 1386-1391(2013)

9. An-Jen Cheng, Yonhua Tzeng, Yi Zhou, Minseo Park, Tsung-hsueh Wu, Curtis Shannon, Dake Wang, Applied Physics Letters 92, 092113 (2008)

10. Yolanda Y. Villanueva, Da-Ren Liu, Pei Tzu Cheng, Thin Solid Films 501, 366 - 369 (2006) 
11. E. Guziewicz, M. Godlewski, T. Krajewski, Ł. Wachnicki, A. Szczepanik, K. Kopalko, A. WójcikGłodowska, E. Przeździecka, W. Paszkowicz, E. Łusakowska, P. Kruszewski, N. Huby, G. Tallarida and S. Ferrari, J. Appl. Phys. 105, 122413 (2009)

12. T.A. Krajewski, G. Luka, P.S. Smertenko, A.J. Zakrzewski, K. Dybko, R. Jakiela, L. Wachnicki, S. Gieraltowska, B.S. Witkowski, M. Godlewski and E. Guziewicz, Acta Physica Polonica 120, 17-21 (2011)

13. K. Okuyama, I. Wuled Lenggoro, Chemical Engineering Science 58, 537-547 (2003)
14. L. Filipovic, S. Selberherr, G. C. Mutinati, E. Brunet, S. Steinhauer, A. Köck, J. Teva, J. Kraft, J. Siegert, F. Schrank, Proceedings of the World Congress on Engineering 2013, Vol. II, WCE 2013, 3 - 5 July, London, U.K (2013)

15. B. Małecka, R. Gajerski, A. Małecki, M. Wierzbicka, P. Olszewski, Thermochimica Acta 404, 125-132 (2003)

16. S. A. Studenikin, N. Golego, M. Cocivera, J. Appl. Phys. 83, 2104 (1998)

17. G. Wisz, T. Ya. Gorbach, P. S. Smertenko , A. Błahut, K. Zembrowska, M. Kuzma, Superlattices and Microstructures 36, 353-358 (2004) 